\title{
Emotion Regulation Strategies in Paramedic Crew Leaders during a Simulated Stressful Task: A Qualitative Inquiry
}

\author{
Branislav Uhrecký1, Jitka Gurňáková1, Martina Baránková ${ }^{2}$ \\ ${ }^{1}$ Institute of Experimental Psychology, Centre of Social and Psychological Sciences, Slovak Academy of Sciences, \\ Dúbravská cesta 9,841 04 Bratislava, Slovak Republic \\ ${ }^{2}$ Institute of Applied Psychology, Faculty of Social and Economic Sciences, Comenius University in Bratislava, Mlynské \\ luhy 4, 82105 Bratislava, Slovak Republic
}

\begin{abstract}
In spite of a large body of research in the field of emotion regulation, this subject has not yet been studied vigorously in naturalistic settings, especially not in the context of task performance. Therefore, it remains uncertain whether predominant theoretical conceptualizations of emotion regulation (e.g., Gross, 1998) can be applied to this sort of situation. In this qualitative study, we aimed to identify emotion regulation strategies of paramedic crew leaders $(n=30)$ in a simulated task with a sudden onset of a stressful incident. For this purpose, we analyzed their emotional behavior (i.e., facial expression, voice volume, body posture and movements etc.) on video recorded performance, and their affective states and emotion regulation strategies based on interviews conducted right after the task. Verbal reports were analyzed via phenomenologically-laden template analysis. We classified emergent strategies into two basic categories: task-related (e.g., attention narrowing, mobilization to action, monitoring) and self-supportive (e.g., emotional distancing, behavioral withdrawal, detachment and selective attention). Results of our analysis suggest that regulatory strategies are largely implemented on an implicit level of processing and their function might be a better criterion for their distinction than a type of mental process.
\end{abstract}

Key words: coping with stress and fatigue, emergency medical service, non-technical skills, naturalistic decision making, simulated task

\section{Introduction}

Despite both emotion regulation and naturalistic decision making being established traditions in psychological research, the two paradigms have barely crossed their paths. With human error being discussed in occupations such as aviation (Wiegmann et al., 2005) or medicine (Kohn, Corrigan, \& Donaldson,
2000), and stress being mentioned as one of the major variables behind it (Sexton, 2000), scientific justification for collaboration between the two mentioned research traditions is obvious. In Japan, almost half of the fatal medical accidents $(46.6 \%)$ are likely caused by the human factor (Uramatsu et al., 2017). The research of naturalistic decision making (Klein, 2008) and closely related non-technical skills (Flin, 2013) has been driven by an ambition to

Correspondence concerning this article should be addressed to Branislav Uhrecký, Institute of Experimental Psychology, Centre of Social and Psychological Sciences, Slovak Academy of Sciences, Dúbravská cesta 9, 84104 Bratislava, Slovak Republic. E-mail: expsuhre@savba.sk ORCID https://orcid.org/0000-0003-3633-1971

Received April 8, 2019 
reduce the human error by studying macrocognitions and teamwork processes of professionals during performance. Coping with difficult subjective states such as stress or fatigue was also acknowledged as a vital skill for enhancing work performance (Kodate et al., 2012). Several studies point to the detrimental effects of stress on both technical and non-technical skills in medicine (e.g., Crewther et al., 2016; Harvey et al., 2012; Krage et al., 2017), which is likely due to a limited acquisition of information or acceleration of pace with trade-offs for accuracy (Maule, 1997). However, experts can be much more immune to losing accuracy compared to novices (Pavlidis et al., 2012). This is in line with claims of Orasanu (1997) and Klein (1997), who both theorize that experts should be least affected by stress in familiar situations where rule-based decisions are optimal, because they rely on intuitive, bottom-up processes.

However, due to methodological difficulties of studying coping with stress in terms of observable and measurable behavior (Shields \& Flin, 2013), naturalistic studies still resort to examining effects of various stressors on physiological markers of stress and performance (Orasanu, 1997), while mechanisms of coping with acute stress remain poorly understood. Therefore, unlike other mental processes, such as situation awareness, decision making or uncertainty management, coping with stress was not conceptualized for the purpose of study in high-fidelity simulated tasks. Because coping strategies are framed as global patterns of behavior and cognition, utilized on regular basis according to most theories and measurement tools (e.g., Carver, Scheier, \& Weintraub, 1989; Folkmann \& Lazarus, 1988), they are not categories sufficient for understanding management of affective states in short time periods (see Boyle et al., 2011). On account of this limitation in the study of coping, Gross (1998) presented emotion regulation as a more nuanced and fine grained conceptualization of how emotions are managed, and he proposed the process model of emotion regulation as a framework for understanding and studying emotion regulation strategies.
The process model still remains the most satisfactory classification of ER strategies in contemporary psychology. Koole (2009) and Gross $(1998,2015)$ find an agreement in differentiating three emotion-regulatory systems attention (e.g., attentional deployment), cognition (e.g., reappraisal, emotional distancing) and body (e.g., ventilation, suppression, relaxation). Gross $(1998,2015)$ distinguishes behavioral strategies of situation selection and situation modification as forms of emotion regulation as well. Cognitive reappraisal - reinterpreting the meaning of a situation into a more positive framing - is widely considered as the most adaptive strategy based on empirical evidence (Gross, 2002). Reappraisal is often put into contrast with suppression, which is an emotion regulatory strategy that inhibits bodily emotional response. The use of suppression has several negative consequences for the subject, including amplification of experienced negative emotion (Gross, 2002) and physiological arousal (Hagemann, Levenson, \& Gross, 2006), and deterioration of cognitive performance (Richards \& Gross, 2000). Turning one's attention away from an aversive stimuli - attentional deployment - is an effective strategy when the intensity of negative emotion is high (Sheppes, Catran, \& Meiran, 2009).

At this point, it is important to note that multiple emotion-regulatory systems or strategies are likely to be implemented in real-life situations (Aldao \& Nolen-Hoeksema, 2013), and the context of task performance consists of some additional particularities and methodological challenges. The lines between desirable action and emotion regulation may become blurred. Working memory's preoccupation with the task may itself serve as a distractor from aversive stimuli, causing the neutralization of emotional experience (van Dillen \& Koole, 2007). Objections were raised with regards to the model's focus on effortful, topdown regulatory strategies (Koole, 2009; Koole \& Rothermund, 2011) and its ability to represent regulatory strategies in real-life conditions (Campos et al., 2011).

The process model was vastly extended and improved over time (see Braunstein, 
Gross, \& Ochsner, 2017; Gross, 2015; Tamir, 2016). Knowledge from self-regulation research and motivational factors were taken into account. Hedonic and instrumental motives were differentiated. Adopting an endless feedback loop between situation (or its perception) and emotion regulation strategy brought a more authentic representation of real-life dynamics in which emotion regulation is taking place. However, Koole and Veenstra (2015) argue that the model still relies on static mental representations as a driving force. Therefore, it is still lacking in capturing the emotion regulation as a process that is interacting with changing environment. At the same time, it remained unchanged in its rigid classification of emotion regulation strategies by the type of process. Rice and Hoffman (2014) believe that a functional perspective, such as the one in theory of defense mechanisms, could be a better a criteria for differentiation between regulatory strategies, compared to process model's schematic approach.

Baumann, Sniezek, and Buerkle (2001) constructed a theoretical model of self-regulation in naturalistic decision making under stressful conditions based on their review of empirical literature. The central assumption of their model is that successful management of task anxiety is dependent on the perception of one's own performance during the task. If one's personal resources and capabilities are perceived as insufficient for the task's demands, the anxiety raises above a tolerable level. The performer is thus at a risk of becoming stuck in a loop between negative self-evaluation of performance and task anxiety. Motivated selfevaluation (focusing on manageable subtasks) is a protective factor against overwhelming task anxiety. However, not all negative or intense emotions need to be regulated as they might carry a cue to a goal-fulfilling action (Mosier \& Fisher, 2010).

The cyclical model of impact of emotions on paramedics' experience during critical incidents, constructed by Avraham, Goldblatt, and Yafé (2014) with a grounded theory approach, postulates similar claims. Negative emotions lead to a sense of professional inadequacy and a lack of perceived control over the task, which further amplifies these emotions. However, paramedics themselves highlight that a certain level of detachment from their emotions is the key protective factor, not positive selfevaluation of their performance. Because detachment is not explicitly mentioned in the process model of emotion regulation (Gross, 1998, 2015), this finding emphasizes the need to study emotion regulation in professional performance as a specific phenomenon. The same principle applies to motivated self-evaluation proposed by Baumann et al. (2001), which might have reappraisal as one component, but it also consists of attention management.

Paramedics have not been given that much attention by researchers of naturalistic decision making, compared to other medical occupations. Assessment manuals of non-technical skills have been created for surgeons, anesthesiologists, and assistants of surgeons (Flin, 2013), but not yet for paramedics. Moreover, as was elaborated in the previous text, coping with stress or fatigue has yet to be put to an extensive empirical probation in the study of medical or even naturalistic decision making. However, coping may not be the most appropriate term to conceptualize management of emotions in naturalistic settings. We argue that emotion (or affect) regulation (Gross, 1998, 2015; Koole, 2009) offers more sufficient terminology for this purpose. A few theoretical models (Avraham et al., 2014; Baumann et al., 2001) attempted to set a starting point for the study of management of distracting emotions while performing in naturalistic conditions, but more effort is required. It is our intention to contribute to this line of research. In this study, we aim to identify, classify and describe emotion regulation strategies in paramedic crew leaders during stressful task on the level of mental processing and observable behavior as well. Our intention was to design a study that would enable us to examine affective states and strategies of their regulation in complex, naturalistic and experience-near settings. 


\section{Methods}

Two sources of data were utilized for the purpose of this study. Both video recorded procedure of paramedic crews during a simulated task and transcribed interviews with paramedic crew leaders were analyzed to accomplish a fusion and triangulation of behavioral and phenomenological approach.

\section{Participants}

Our research sample consisted of 30 paramedic crew leaders (17 male, 13 female) of Czech and Slovak nationalities. The age of the participants ranged from 23 to 47 years $(A M=$ $31.17, S D=6.67, M d n=29.50)$. Each crew consisted of the crew leader, paramedic driver, and paramedic - operator, with the exception of two crews having one extra member. However, in our study, we focused solely on crew leaders. One of the crews was excluded from our research sample due to technical issues of the video record from our main camera. Three crews consisting of medical students were included, while all others were professional paramedics with a various length of practice in their occupation, ranging from 1 to 26 years $(A M=7.33, S D=5.80, M d n=7)$.

Participants were recruited at an international paramedic competition Rallye Rejvíz 2017. After an agreement with the organization board of this competition, every paramedic that was interested in competing in this event had to explicitly agree with taking part in data collection as a participant in order to be registered. Each registered competitor received information about the planned research a month before the start of the competition. Specifically, the information mentioned video recording of their performance during one of the task and a post-task interview with the crew leader. Our entire methodology had been approved by the ethical board of Slovak Academy of Sciences.

\section{Data Collection}

Paramedic crews were video recorded while performing a simulated task. Four static cameras were placed in a room where the task was taking place and one camera was handled by a cameraman who was targeting the crew leader. An interview with the crew leader was carried out right after the task had been completed. The semi-structured interview had a format of a retrospective verbal protocol with an intention to make the crew leader recall and describe his/her experience during the task including his/her intentions, thoughts, emotions and means of coping with them. The interviewer was supposed to make the interviewee as specific as possible, so that his/her experience of the task could be reconstructed on a timeline (more in Data analysis). Interviews were conducted by a group of three researchers and they took from 10 to $15 \mathrm{~min}$ utes.

\section{Task}

The task named "Grill" started as a routinetype mission, even though paramedic crews had been informed beforehand about the possibility of a domestic violence. On the scene, one paramedic crew (played by figurants) was taking care of a pregnant drug-addict and the competing crew was supposed to take care of an injured female pensioner who was denying any domestic violence, and her distraught sister who was blaming the drug addict. After a few minutes, the drug-addict stabbed a member of the other paramedic crew right after the arrival of a police crew (who are also competitors, not figurants, and therefore their behavior was not scripted). The aggressor (i.e., the drug addict) ran to the backroom and was threatening the police with a knife. Stabbing of the paramedic caused an acute bleeding, so the competing paramedic crew was supposed to attend, stabilize and monitor the injured paramedic, and possibly take care of the aggressor if she got injured by the police. The pair of pensioners, who needed to be properly examined, was supposed to have an antagonistic reaction if the policemen shot the aggressor in their sight. Paramedic crew leaders were supposed to report the means and directions 
of transportation of every patient to dispatching at the end of the task.

\section{Data Analysis}

A codebook for emotional behavior (Appendix 1) was developed by a certified FACS (Facial Action Coding System; Ekman \& Friesen, 1978) coder after analyzing video records of every crew during the task "Grill". The codebook was largely inspired by basic emotions and emotion families (see Ekman, 1977; Ekman \& Cordaro, 2011; Wallbott, 1998) and listed 25 categories of emotional behavior. The certified coder schooled one of the researchers in this coding tool, so he could independently code emotional behavior of crew leaders. Subsequently, all video records were coded by both coders, the codes were compared, discussed and consensus on mismatched data segments was reached. In addition, the paramedic crew leaders' behavior was described as precisely as possible and notable situational cues were also recorded in writing.

Interviews were transcribed and analyzed via template analysis to identify affective states, goals and regulatory strategies of crew leaders during the task. We applied the combined, exploratory-theoretical approach. Especially our effort to identify regulatory strategies was theoretically grounded in contemporary knowledge as they are conceptually complex processes. A list of regulatory strategies was constructed by authors of this study prior to analysis based on four articles (three review articles and one meta-analysis) that provided extensive summaries of strategies (Gross, 2015; Koole, 2009; Peňa-Sarrionandia, Mikolajczak, \& Gross, 2015; Webb, Miles, \& Sheeran, 2012). We did not include macro-level means of emotion management such as coping styles, mindfulness meditation, etc. Strategies on our list were grounded in the process model's framework and each of them was precisely defined. Strategies proposed by Avraham et al. (2014) and Baumann et al. (2001) were also added to this list. The list was applied in data analysis as a coding system that was open to adjustments and changes based on data. Be- cause any statement regarding cognitive processing, attention direction or behavioral action might indicate emotion regulation without the subject's explicit awareness (Koole \& Rothermund, 2011), more latent and interpretative coding procedure had to be applied at times to identify regulatory strategies. Every statement indicating emotion regulation was coded initially and stricter selection process was applied when re-evaluating our codes. In comparison, affective states and goals were coded more semantically (see Guest, McQueen, \& Namey, 2011). A codebook for interviews was created by one of the authors and another coder tested it on a limited dataset. After initial comparisons and consultations, adjustments to the codebook were made and both coders used it to analyze the entire dataset. Inter-rater agreement was calculated and reached moderate levels $(\mathrm{k}=0.66)$, but both coders were at liberty to suggest their own codes via memos if they found it appropriate. Data segments where agreement was not found or new codes were suggested were reappraised afterwards.

After video records and transcriptions of interviews were analyzed, timeline of the task "Grill" for every paramedic crew leader was constructed using both sources of data. Interviews proved to be rich enough to enable matching the reported subjective experience with behavioral data without much doubt and confusion regarding their placement on a timeline (illustration of a data segment on a timeline is in Appendix 2). During this triangulation, we adjusted our categories for regulatory strategies and even proposed a few more (more in results). We looked for patterns in our timelines regarding regulatory strategies - what is the situational context of implementation, which affective state is regulated, what is the participant's behavior, etc. - in order to describe them in the greatest possible depth. We distinguished time frames where a good fit between the two sets of our data was not achieved (i.e., the self-reported and observed affective state did not match), which resulted in a greater level of ambiguity and interpretation. One of the identified subcategories - de- 
tachment and selective attention - was inferred based on this lack of fit.

\section{Results}

Our analysis produced 14 subcategories of emotion regulation strategies which were classified as either task-related or self-supportive. We abandoned the classification system of our prior coding scheme based on the process model, because the differentiation by a type of process was not a good fit for the content of identified subcategories. Identified strategies were not distinguishable purely on merits of process-type. Functional approach seemed more appropriate. The primary intention of task-related strategies was to enhance performance, which included regulation of distractive emotions and management of emotional arousal to meet the task's demands. Tolerable and activating level of distress, which leads to a desirable form of action, is a more desirable effect of task-related strategy compared to a positive mood or relaxation. On the other hand, selfsupportive strategies served the purpose of attenuation of negative emotions and/or induction and amplification of positive emotions, and they had no direct connection to taskrelated action. In presentation of our results, we describe the most comprehensibly portrayed strategies in greater detail. All emergent strategies are summarized and shortly characterized in Table 1.

Table 1 Overview of emergent emotion regulation strategies and frequencies of their occurrence

\begin{tabular}{|c|c|c|c|}
\hline & Strategies & Short definition & $\begin{array}{l}\text { Occurred in } \\
n \\
\text { participants }\end{array}$ \\
\hline \multirow{8}{*}{ 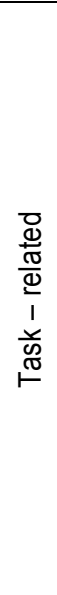 } & Attentional narrowing & $\begin{array}{l}\text { Focusing one's attention to a specific set of } \\
\text { stimuli or a subtask. }\end{array}$ & 16 \\
\hline & Mobilization to action & $\begin{array}{l}\text { Directing emotional arousal towards immediate } \\
\text { action. }\end{array}$ & 14 \\
\hline & $\begin{array}{l}\text { Mobilization to deliberative } \\
\text { concentration }\end{array}$ & $\begin{array}{l}\text { Attempt to think and plan sequentially, step-by- } \\
\text { step. }\end{array}$ & 12 \\
\hline & Distancing from the scene & Viewing the situation as a whole. & 11 \\
\hline & Vigilance & $\begin{array}{l}\text { A state of readiness to react to any critical } \\
\text { event. }\end{array}$ & 13 \\
\hline & Monitoring & Keeping specific stimuli in check. & 11 \\
\hline & $\begin{array}{l}\text { Relying on a rule-based } \\
\text { procedure }\end{array}$ & $\begin{array}{l}\text { Finding comfort in sticking to guidelines and } \\
\text { automatized processes. }\end{array}$ & 9 \\
\hline & $\begin{array}{l}\text { Reflection of previous } \\
\text { decisions and events }\end{array}$ & $\begin{array}{l}\text { Dealing with a disappointment by asking } \\
\text { oneself whether an aversive event was } \\
\text { preventable. }\end{array}$ & 4 \\
\hline \multirow{6}{*}{ 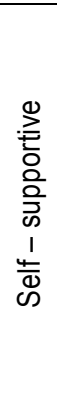 } & Emotional distancing & $\begin{array}{l}\text { Observing one's own emotions from a } \\
\text { distanced perspective. }\end{array}$ & 9 \\
\hline & $\begin{array}{l}\text { Establishing a sense of } \\
\text { connection with the other }\end{array}$ & $\begin{array}{l}\text { Seeking the experience of being in contact with } \\
\text { another person. }\end{array}$ & 5 \\
\hline & $\begin{array}{l}\text { Detachment and selective } \\
\text { attention }\end{array}$ & $\begin{array}{l}\text { Disconnection from one's emotions, directing } \\
\text { attention away from negative aspects of } \\
\text { performance. }\end{array}$ & 7 \\
\hline & Behavioral withdrawal & Withdrawal from a dangerous situation. & 6 \\
\hline & Venting & Reduction of tension by behavioral expression. & 6 \\
\hline & Positive self-talk & Encouraging oneself by positive statements. & 3 \\
\hline
\end{tabular}


Table 2 Summary of the descripted experience and behavioral signs of major task-related emotion regulation strategies

\begin{tabular}{|c|c|c|}
\hline Strategy & Experiential component & Behavioral signs \\
\hline 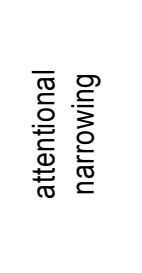 & $\begin{array}{l}\text { - absorption with a set of stimuli or a } \\
\text { subtask } \\
\text { - some stimuli or all surroundings are } \\
\text { blurred or completely disappeared } \\
\text { - } \text { awareness of emotional state is } \\
\text { dissolved in favor of a limited number } \\
\text { of situational cues and action }\end{array}$ & $\begin{array}{l}\text { - focused on the current task, not looking around } \\
\text { - does not respond to stimuli or requests from } \\
\text { his/her team members } \\
\text { - reverts his/her attention back to a previous } \\
\text { activity if disturbed } \\
\text { - reacts surprised when informed about course of } \\
\text { events not in his/her immediate proximity }\end{array}$ \\
\hline 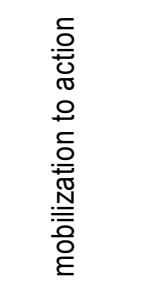 & $\begin{array}{l}\text { - feeling time pressure and urge to act, } \\
\text { even when not understanding the } \\
\text { meaning of what is happening in the } \\
\text { situation } \\
\text { - feeling professional responsibility to } \\
\text { act } \\
\text { - energizing one's own body }\end{array}$ & $\begin{array}{l}\text { - a sense of emergency in performed procedures } \\
\text { - acceleration of pace } \\
\text { - insisting on colleagues to assist quickly } \\
\text { - increased volume of voice, quick pace of } \\
\text { speech } \\
\text { - proptosed eyes and slightly open mouth, similar } \\
\text { but not as intense as worry } \\
\text { - checking clocks }\end{array}$ \\
\hline 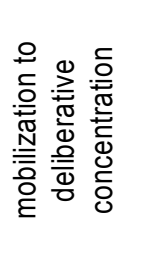 & $\begin{array}{l}\text { - the situation is perceived as } \\
\text { suddenly overwhelming } \\
\text { - a step-by-step thinking brings a } \\
\text { sense of order into chaotic situation }\end{array}$ & $\begin{array}{l}\text { - does not act, remains vigilant towards the } \\
\text { situation, might even appear confused about } \\
\text { the appropriate course of action } \\
\text { - action is either hesitant or rushed, but with } \\
\text { moments of interruption } \\
\text { - summarizing and discussing information with } \\
\text { colleagues }\end{array}$ \\
\hline 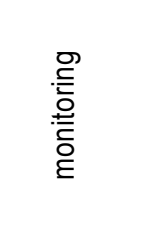 & $\begin{array}{l}\text { - having a specific expectation or } \\
\text { suspicion that something might get } \\
\text { out of control } \\
\text { - tension arising from this expectation } \\
\text { - keeping that aspect of situation in } \\
\text { check by attention or direct action }\end{array}$ & $\begin{array}{l}\text { - being watchful towards an unstable aspect of } \\
\text { the situation } \\
\text { - examining the patient anxiously, checking for } \\
\text { some symptoms or vital signs multiple times }\end{array}$ \\
\hline 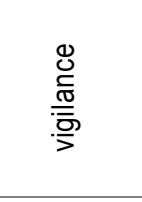 & $\begin{array}{l}\text { - tension arising from an expectation } \\
\text { of some dangerous, averse event } \\
\text { - being in a state of readiness to react } \\
\text { to a change of situation }\end{array}$ & $\begin{array}{l}\text { - visually scanning the scene } \\
\text { - reacting to sounds (turning of the head) } \\
\text { - being attentive, but suspicious towards } \\
\text { reports of people on the scene, asking } \\
\text { about specific details }\end{array}$ \\
\hline 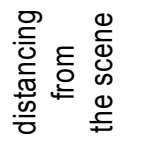 & $\begin{array}{l}\text { - stimulating or routine level of stress } \\
\text { - being above the situation } \\
\text { - situation is observed as a whole and } \\
\text { thinking is almost effortless }\end{array}$ & $\begin{array}{l}\text { - instructing and organizing the work of } \\
\text { colleagues } \\
\text { - no visible emotional expression, appearing } \\
\text { calm and collected }\end{array}$ \\
\hline
\end{tabular}


Specific behavioral and experiential features of task-related strategies (except minor ones) are presented in Table 2. The same was not done for self-supportive strategies, as they were less tied to specific moments of task completion (or time units in our timelines), and therefore we assumed textual description to be sufficient. Because we had to settle for a limited set of sample due to constraints of the competition, we could not achieve a satisfactory theoretical saturation for every subcategory we identified in our analysis. We did not want to exclude less saturated subcategories from the results as they might be elaborated in future studies. The density of our data was satisfying for most subcategories of emotion regulation except for three - ventilation, establishing a sense of connection with the other, and positive self-talk.

\section{Task-Related Strategies}

\section{Attentional Narrowing}

Referred to as the so-called tunnel vision, often following mobilization to action and accompanied by the use of intuitive rule-based procedures, this strategy was characterized by an attentional preoccupation with a specific set of stimuli or a specific subtask while other stimuli and subtasks are being ignored. The most typical situation of use was during an effort to stop the acute arterial bleeding and stabilize the patient, which was accompanied by a sense of trust that the police will keep the paramedic team safe. Surroundings became acknowledged once a sense of control over an urgent subtask was maintained. This could take just one minute or it could last until some of the patient's vital signs were checked several times. Self-awareness was also compromised by the use of this strategy, as was explicitly noted by some of our participants.

We were safe, because police was on the scene, so I could take care of my colleague [the injured figurant] and I didn't feel anything... I guess, because I'm used to making my tunnel for what I need to do. And I totally let my surroundings go, so I just found out there's another patient [the aggressor] right before the end of the task, because l'd been so focused on my patient, so I had no idea about what's going on around me. (P1/26)

The tunnel thing, that's adrenaline, you know. The adrenaline is pumping, one is just running through it and he only looks just at what's in front of him, you know. No interest in what's on one side or the other. (P3/72)

I usually feel like... empty, emotionally. I'm just thinking about what needs to be done and maybe I feel something, but l'm not aware of it. (P29/53)

The implementation of this strategy was not always successful. Two participants report using this strategy, but feeling highly aroused, in danger and showing signs of fear and alertness towards the physical conflict between the police and the aggressor. However, the strategy was not implemented only as an absorption with a high-priority subtask during emergency, but also as a means to filter out frustrating distractors when the situation was still calm.

Of course, you need to filter out those people, those that don't matter at that moment. And people do complain quite often as the old lady did there. (P7/16)

\section{Mobilization to Action}

When the situation was interpreted as an emergency, a sense of responsibility and a need to act arose. These feelings were associated with their professional role as a paramedic and as a leader. The fact that it was another paramedic, a colleague, who was in a need of help, was also significant for them. A belief that a paramedic is supposed to act and not be stunned by any event was explicitly present in some verbal reports.

I know I need to do something, that I'm not there to break down. That's why I'm doing this job. (P6/064)

It's some kind of mechanism - like we have to do something. That someone needs help, probably even the factor that it's our colleague [plays a role]. (P28/44)

Even if the paramedic crew leader did not fully comprehend the situation, was unsure 
about his or others' safety, or was in a freeze reaction, this urging to act was often expressed in a confused tendency to walk towards the injured paramedic. In some cases, this was an automatic, reflex-like reaction without any moment of hesitation.

Priorities changed and that, like... alertness of organism and mobilization to act immediately [changed also]. (P15/050)

It's like I was born this way that I have to press on the wound. Like you don't even think about it. You just rush and do it. (P23/068)

Behavioral manifestations of mobilization to action included acceleration of pace, a sense of emergency in sensorimotor operations, and insisting on colleagues to assist quickly.

\section{Mobilization to Deliberative Concentration}

Several participants experienced the situation as overwhelmingly stressful, chaotic and engulfing, and may have displayed either shock or fear. Above all, they acted as confused (being stuck between multiple courses of action or switching from one operation to another) or uncertain, lacking in natural fluidity of behavior. As a result of this strategy, action was rushed at some moments, but there were multiple moments of interruption when the leader was stuck.

This typically occurred to less experienced paramedic crew leaders ( $n=5$, avg. length of practice: 2.4 years) during and immediately after the incident with the police. For instance, one of our participants in this study reacted with vigilance and confusion during the incident, undecided whether to assist colleagues whose reaction was quicker or to stay with the pensioners to keep them safe. He described his means of dealing with the emotional arousal as an attempt to approach demands of the situation with sequential thinking.

"I guess I'm trying to focus on stuff singularly... like... what should I do first, what's next... that I refuse to accept that this is not going so well, we're not gonna make it, but l'd rather tell myself 'well, now I need to do this, then I need to do that'." (P29/094)
In more experienced paramedics ( $n=4$, avg. length of practice: 9.25), this strategy was applied after initially reacting on impulse to the acute bleeding and narrowing their focus to the paramedic figurant for a period of time. As they were trying to acknowledge other situational aspects, they had to exert some extra effort to compensate for their lack of perspective and to have a sense of control. They described their cognitive processing as sequential and systemizing. On a behavioral level, collecting, summarizing or discussing information in communication with colleagues was observed.

I was thinking rationally about it, I was thinking we might need some psychological support for witnesses, those who saw the injured paramedic. So I was thinking about the next step. (P25/062)

\section{Monitoring}

When a certain aspect of the task seemed out of control or was likely to cause some trouble in the leader's perception, he remained watchful and prepared to react. Most typically, he would be concerned about the aggressor before the incident took place, which was provoked by his verbal conflict with one of the pensioners. There was a tendency to turn towards the source of suspicion or even come to the figurant paramedic crew to make sure they're handling their patient.

Monitoring also occurred when observing the physical conflict between the police and the aggressor or during stabilization of the wounded paramedic when checking his vital signs multiple times, sometimes overlapping with narrowed focus. The difference between the two strategies is that narrowed focus includes taking action to fix something that is out of order as a vital component, while in monitoring the stimuli is only a prospective cue for action, likely resulting in lesser demands on concentration. Thus, refocusing towards different stimuli or operation would happen more fluidly.

I was checking my colleagues who were examining them [pensioners] and because the 
colleague [from figurant crew] told us they're taking care of the restless woman [the aggressor], I wanted to keep an eye on her. (P2/020)

\section{Vigilance}

Compared to monitoring, vigilance had no specific focus. Many participants had an expectation that some danger might be present in the situation, but did not stick to any hypothesis due to their previous experience with being unpleasantly surprised in paramedic competitions. Mostly, they expected some form of aggression and set themselves into a state of readiness to react to any significant event, but hypervigilance to any sort of danger (e.g., gas poisoning) expressed behaviorally as visual scanning of the scene or hyper-reactivity to sounds was also present. This could lead to catching on irrelevant situational cues. For instance, one of the crew leaders was curious when one of the pensioners mentioned they had been making coffee prior to paramedics' arrival, because he considered the possibility of a gas leak.

I was looking around every corner because I was expecting some kind of a catch. That lady was saying they had been making coffee, so I was thinking there might be a gas leak, that there might be some danger. (P2/036)

Hypervigilant participants experienced the first phase of the task as quite demanding, while participants vigilant on a lower level described their experience as a non-disturbing tension.

Unfortunately, you expect at some subconscious level that something is going to happen behind your back on these competitions. (P17) 08)

\section{Distancing from the Scene}

Initially identified in the same category as compensation through deliberative concentration, distancing from the scene was later distinguished as a separate regulatory strategy after triangulation with behavioral data. While also having the aim of comprehending and handling all unresolved aspects of the situa- tion, some participants described their cognitive processing as less effortful, more holistic, and relaxed. This was behaviorally manifested as a tendency to step outside the scene and observe it not just in a mental, but also physical distance. They generally showed no signs of emotion in their behavior and they felt above the situation, which was visible in their tendency to instruct their colleagues or provide them with information while speaking calmly.

Like I said, it's a competition, so I didn't feel that much. I was more concerned with handling it logistically - to help our patient and also to take care of the old ladies here. I felt no emotions at that moment. (P10/30)

I was with my colleagues at that moment and I was telling them what to do, how to proceed, what should be checked... (P2/024)

\section{Minor Task-Related Regulatory Strategies}

Few other strategies beyond the aforementioned ones were identified, but were not as prevalent and rich in participant's verbal reports. Reflection of previous decisions and events was present when crew leaders felt frustrated and disappointed with paramedic's injury or the pregnant woman's death. They were obsessively asking themselves whether they could have prevented this event or whether it was their fault. In terms of emotional behavior, this was manifested as attenuation - being passive, absent-minded, and mentally isolated from what was happening. Relief or disappointment was observed by the end of the task. Although likely adaptive in some forms after the task, this seemed to be deteriorative to their performance.

Also, some participants found comfort in relying on a rule-based procedure. They reported that the clarity of guidelines for taking care of acute arterial bleeding and their internalized knowledge of these guidelines made them feel confident in what they were doing, but this was also the case for one participant, who applied the ABCDE heuristic when examining the injured pensioner after being observably confused and insecure in reaction to the incident. 


\section{Self-Supportive Strategies}

\section{Emotional Distancing}

Emotional distancing, in a sense of assuming a distanced position towards one's own emotions, was largely dependent upon an interaction with the environment. If the situation was perceived as a game or a sport, emotions were still elicited by external events, but one could remain safe from engulfment by their intensity. However, it is unclear when this is caused by conditions of the competition (such as the presence of referees in the room, authenticity of figurants' performances, etc.) and when this is a motivated emotion regulation. It is very likely that both factors come into play, but to draw a precise line between them is difficult from our data. However, at least one of our participants reported consciously reminding himself of the nature of the situation.

(What helped you to handle this situation?) This time? I reminded myself it's a competition. (P21/50)

It's different in real-life. I'd be more scared, definitely. More fear, more respect. There, I have this subconscious sense of safety because it's a competition. (P11/008)

Relieving smile or joking was observable on those participants who described their emotional attitude towards the task as distanced multiple times, usually in a reaction to the rambling of one of the pensioners.

Establishing and Maintaining a Sense of Connection with the Other

Another mechanism or regulating one's affective state that was co-implemented in interaction with the environment was founded on experiencing some form of connection with another person, which could have been a colleague or a figurant. The familiarity of colleagues was a good regulator in words of our participants and it was not just their presence in a passive sense of the word that had this effect, because crew leaders were intuitively but actively reminding themselves of their presence.
(What was is it specifically that helped you to handle this situation?) Well, my colleagues, my contact with them. Verbal or nonverbal, their body language. We're a well-coordinated unit, we're used to each other. (P15/097)

A few direct behavioral manifestations were observed, which includes touching or having a common relieving smile, indicating that this process is enacted rather under the skin than outwards.

Communication with figurants could also be a way of managing one's own emotions, though this was reported in a number of ways. A simple exchange of first names could have a regulating effect, but this was also reported about soothing figurants' emotions. A tendency to calm and ground distraught pensioners was particularly apparent in crew leaders that were shocked and overwhelmingly stressed by the incident.

For instance, calming that miss [helped me feel better] and I tend to touch patients by the shoulder when I see they might be disturbed, maybe because I am disturbed too, so that's definitely automatic. (P29/64)

\section{Detachment and Selective Attention}

Discrepancies between participants' verbal reports and observable behavior can often be caused by imperfections of cognitive apparatus, but in some participants they happened to be so severe they could be interpreted as implicitly motivated. Their emotional distress was noticeable in forms of shock, freeze reaction, worries, confusion, uncertainty, helplessness, etc., but signs of this distress were absent in their verbal reports. For instance, when asked directly about their freeze reaction to the stressful incident, two participants answered they are not even aware this happened and they believed they had reacted immediately to the figurant's bleeding. However, this discrepancy was not strictly tied to the incident when the paramedic figurant was stabbed, but manifested throughout their whole narrative about the course of this task.

After an initial stressful reaction to the incident, their behavior became inhibited to the 
point of giving the impression of carelessness, but their facial expression had mild features of worry (e.g., redness in face, open mouth, proptosed eyes). They answered the interviewer's questions usually in terms of mechanistic description of their behavior and they were either unaware of any emotional reactions or unable to elaborate their answer beyond terms such as stressful or difficult. A tendency to describe their approach and overall performance as professional and well-handled was present in some of them.

I don't even know if something is going through my head when I'm on the job. You just do what you're supposed to do, you think about diagnosis and there's nothing else [on my mind]. (P26/16)

\section{Minor Self-Supportive Strategies}

Some participants interpreted the incident as a danger to them and/or to pensioners in the room and immediately decided to either flee away from the scene or step further away to keep a distance, which can be evidently identified as a behavioral withdrawal. However, this could be classified as a task-related strategy when their intention was to take pensioners with them to keep them safe.

Though not reported in interviews by participants, signs of behavior that could be marked as venting were observable, but they were not too frequent. The most significant sign were sarcastic remarks, usually towards one of the pensioners who was very outspoken, but only once was this expressed with visible frustration and anger (e.g., headshaking, raised tone of voice). Unintentional body movements (e.g., pulling up sleeves, playing with one's hair) do also fit into this category. Also, positive selftalk occurred in three participants, either reported in an interview or observed on a video record (e.g., saying aloud "great, that should be it").

\section{Discussion}

Two broad categories of emotion regulation strategies emerged in our qualitative analysis
- task-related and self-supportive. Task-related strategies are largely overlapping with macrocognitive processes such as situation awareness, uncertainty management, decision making, etc. For a long time, all mental processes in naturalistic decision making paradigm were listed as macrocognitions while their emotional component was omitted (Mosier \& Fischer, 2010). Therefore, instead of just adding a whole new package of mental processes to the existing body of knowledge about naturalistic decision making, results of our study are pointing out a rather different function of previously described processes. Phenomena such as tunnel vision were already described in literature concerning situation awareness (e.g., Endsley, 1995), but their emotion-regulatory function was not discussed. How professionals cope with difficult affective states during task performance remains a huge question mark in existing literature, maybe because it is not something that professionals do separately from procedures directed at task completion.

Holistic and functional nature of emotion regulation strategies in naturalistic setting is another implication of our qualitative analysis. Attentional processes seem to be of high importance, but most strategies have multiple components or occur simultaneously with others, such as the narrowed focus that had cognitive and behavioral elements, and often initially co-occurred with mobilization to action. This is line with findings of Adamovová and Halama (2013), who found through an abbreviation of critical decision method that paramedics regulate their emotions mostly by directing their attention and utilizing their emotional arousal towards desirable action.

In comparison to strategies proposed by Gross $(1998,2015)$ in the framework of process model of emotion regulation, all of the task-related strategies present novel findings. Nevertheless, this is not too controversial, in our perspective, considering that the process model framework was originally designed for the study of hedonically motivated emotion regulation. Our study hints at a possible necessity of a different framework for emotion 
regulation motivated by external goal. However, the distinction between task-related and selfsupportive strategies is not without its predecessor, as it is quite compatible with problemand emotion-focused coping of Lazarus and Folkman (1984).

While some of our participants declared that the use of intuitive rule-based procedures had boosted their self-confidence, mobilization towards deliberative concentration was also identified as a task-related regulatory strategy. While the classic macrocognitive framework would attribute this simply to a lack of automatized processes in inexperienced crew leaders (Klein, 2008), alternative explanation may come into play. Because the associationbased system produced an output (i.e., emotional response) that preoccupied explicit processing, the action tendency of this response takes priority and bodily signals of intuition are not available to the conscious mind (for a review on effects of emotion on information processing, see Yiend, 2010). However, this interpretation is very much an open to debate.

Two of the self-supportive strategies were quite prevalent - emotional distancing and detachment along with selective attention (which happened to co-occur in our research sample). Both of them appeared to have a character of a generalized attitude or perhaps even a personality pattern, because they were mostly not applied in a specific moment, but carried out throughout the whole experience during the task. This is why we distinguished emotional distancing from distancing from the scene, which was implemented at specific time frames. It is likely that the emotional distancing is a prerequisite for the other, but a paramedic could have described his task experience from a distanced perspective without explicitly reporting or exhibiting signs of distancing from the scene. Emotional distancing is a well-established strategy in the process model framework (Ochsner \& Gross, 2008) and could be considered as an adaptive strategy according to some empirical studies (e.g., Kross et al., 2012; Webb et al., 2012). Adaptiveness of emotional distancing is also supported by low emotional awareness in good female paramedic decision makers in the lowa Gambling task, according to the study of Pilárik and Sarmány-Schuller (2011). We cannot provide quantitative evidence for this claim in our study, but the use of this strategy was associated with reporting the experienced level of stress as positively stimulating.

In line with studies of Avraham et al. (2014) or Clompus and Albarran (2016), detachment was also present in paramedic crew leaders. As was noted earlier, detachment is not mentioned in the process model (Gross, 1998, 2015), likely because it is concerned with explicit forms of emotion regulation, while this phenomena remarkably resembles the construct of alexithymia (Taylor, Bagby, \& Parker, 1999) and repressive coping style (Weinberger, 1990). Both of them are presumed to operate on implicit level of processing. Detachment is even classified as a dissociative process by some authors (e.g., Brown, 2006). We decided to put detachment and selective attention into one bin because that is what emerged from our data, but they may be two separate strategies. Selective attention might be considered as an equivalent of attentional deployment (Gross, 1998, 2015).

Two of the most famously studied regulatory strategies - reappraisal and suppression (Gross, 2002) - were not mentioned by our participants. In the case of reappraisal, this can be explained by cognitive demands of this strategy (Koole, 2009; Sheppes et al., 2009). Implementation of reappraisal could decrease cognitive resources available for completing the stressful and time-limited task. Signs of positive self-talk were found in our data, which might indicate the use of cognitive reappraisal, but it also might be a way of preserving focus on the task (Manera et al., 2014).

The explicitness and implicitness of implemented regulatory strategies is another issue that arises from our findings. Though it is not possible to draw precise lines between implicit and explicit strategies (or their components), this is not an uncommon issue as current neuroscientific evidence suggests that boundaries between implicit and explicit processing are gradual and blurred (Miller \& 
Schwarz, 2014). Most mental operations or their components function on both levels of processing. Some instances of strategy use might be classified as either explicit or implicit. For example, attentional narrowing was often described as a reflex-like mechanism of dealing with a situation, but it was also characterized as a conscious effort to filter out unwanted stimuli on some occasions. In other instances, strategy could have an explicit goal and implicit implementation (e.g., vigilance) or vice versa (e.g., reflection of previous decisions and events), but to claim that this was always the case with a specific strategy would be an oversimplification at this point. The fact that the proportion of implicit processing in strategy choice and implementation might also be determined by previous experience and automatization should be considered as well. Therefore, this is an issue of great gravity, but further investigation is necessary for valid answers.

\section{Limits of the Study}

Limits of our study are related to ecological validity of the simulated task and to validity of retrospective verbal protocols. As for the limits of the task "Grill", the lack of a real menace is a strong factor. It was admitted by a number participants that an escape from the room would be their first choice if this situation happened in reality, but the simulated nature of the task enabled them to stay cool and emotionally distanced from the situation. The absence of script for police crews resulted in largely varying conditions, which complicates the generalization of our results. On the other side, the particularity of this task (physical assault and acute bleeding) means that the results cannot extend beyond situation of emergency and different type of strategies might be present in different situations in the work of a paramedic. Besides, due to characteristics of a paramedic competition, we were unable to follow the established rules of sampling and theoretical saturation in qualitative research precisely, as we had to stick to the data set that was available. Satisfactory theoretical saturation was still achieved for a vast majority of identified regu- latory strategies. Data set painted a very varied picture about some of the less frequent and less comprehensively described strategies which resulted in difficulties with fitting them into a unifying conceptualization.

Inaccuracies in recall of past experience present a limit of retrospective verbal reports. These might occur because of the automaticity of mental processes and the mind's tendency to fill gaps in introspection in order to tell a coherent narrative (Nisbett \& Wilson, 1977 ), even when the recalled experience is quite recent. For this reason, it would be more valid to carry out the retrospective verbal protocols with the assistance of the crew's video recorded performance being replayed, but this was not technically accomplishable in our conditions.

Nevertheless, we believe our results are a valuable contribution to the study of emotion regulation in naturalistic setting because data collection was done using a high-fidelity simulated task and because of validation through triangulation of verbal reports with video recorded performance. Even though simulated tasks have their shortcomings, compared to real-life situations, the physiological stress during simulation can reach the same levels (Ghazali et al., 2018).

\section{Acknowledgement}

This work was supported by grant agency VEGA, no. 2/0070/18, Cognitive and social skills supporting the quality of performance of emergency medical services' professionals.

\section{References}

Adamovová, L., \& Halama, P. (2013). Emócie a emočná sebaregulácia $v$ práci zdravotníckych záchranárov: Kvalitatívny prístup [Emotions and emotion regulation in the work of paramedics: Qualitative approach]. In J. Gurňáková a kol. (Ed.), Rozhodovanie profesionálov: Sebaregulácia, stres a osobnost' [Expert decision making: Self-regulation, stress, and personality] (pp. 247-266). Bratislava: Ústav experimentálnej psychológie SAV.

Aldao, A., \& Nolen-Hoeksema, S. (2013). One versus many: Capturing the use of multiple emotion 
regulation strategies in response to an emotioneliciting stimulus. Cognition \& Emotion, 27(4), 753760. doi: $10.1080 / 02699931.2012 .739998$

Avraham, N., Goldblatt, H., \& Yafé, E. (2014). Paramedics' experiences and coping strategies when encountering critical incidents. Qualitative Health Research, 24(2), 194-208. doi: 10.1177/ 1049732313519867

Baumann, M. R., Sniezek, J. A., \& Buerkle, C. A. (2001). Self-evaluation, stress and performance: A model of decision making under acute stress. In E. Salas \& G. Klein (Ed.), Linking expertise and naturalistic decision making (pp. 139-158). New York, London: Psychology Press. doi: 10.4324/ 9781410604200

Boyle, E., Kennedy, A. M., Doherty, E., O'Keeffe, D., \& Traynor, O. (2011). Coping with stress in surgery: The difficulty of measuring non-technical skills. Irish Journal of Medical Science, 180(1), 215-220. doi: 10.1007/s11845-010-0578-Z

Braunstein, L. M., Gross, J. J., \& Ochsner, K. (2017). Explicit and implicit emotion regulation: A multi-level framework. Social and Affective Neuroscience, 12(10), 1545-1557. doi: 10.1002/9781119170174. epcn415

Brown, R. J. (2006). Different types of "dissociation" have different psychological mechanisms. Journal of Trauma and Dissociation, 7(4), 7-28. doi: 10.1300/J229v07n04_02

Campos, J. J., Walle, E. A., Dahl, A., \& Main, A. (2011). Reconceptualizing emotion regulation. Emotion Review, 3(1), 26-35. doi: 10.1177/ 1754073910380975

Carver, C. S., Scheier, M. F., \& Weintraub, J. K. (1989). Assessing coping strategies: A theoretically based approach. Journal of Personality and Social Psychology, 56(2), 267-283. doi: 10.1037//00223514.56.2.267

Clompus, S. R., \& Albarran, J. W. (2016). Exploring the nature of resilience in paramedic practice: $A$ psycho-social study. International Emergency Nursing, 28(1), 1-7. doi: 10.1016/j.ienj.2015.11.006

Crewther, B. T., Shetty, K., Jarchi, D., Selvadurai, S., Cook, C. J., Leff, D. R., . . \& \& Yang, G. (2016). Skill acquisition and stress adaptations following laparoscopic surgery training and detraining in novice surgeons. Surgical Endoscopy, 30(7), 2961-2968. doi: $10.1007 / \mathrm{s} 00464-015-4584-0$

Derakshan, N., Eysenck, M. W., \& Myers, L. B. (2007). Emotional information processing in repressors: The vigilance-avoidance theory. Cognition and Emotion, 21(8), 1585-1614. doi: 10.1080/ 02699930701499857

Ekman, P. (1977). Biological and cultural contributions to body and facial movement. In J. Blacking
(Ed.), The anthropology of the body (pp. 39-84). London: Academic Press.

Ekman, P., \& Cordaro, D. (2011). What is meant by calling emotions basic. Emotion Review, 3(4), 364370. doi: $10.1177 / 1754073911410740$

Ekman, P., \& Friesen, W. (1978). Facial action coding system: A technique for the measurement of facial movement. Palo Alto: Consulting Psychologists Press.

Endsley, M. (1995). Measurement of situation awareness in dynamic systems. Human Factors, 37(1), 65-84. doi: 10.1518/001872095779049499

Flin, R. (2013). Non-technical skills for anesthetists, surgeons and scrub practitioners. In The Health Foundation, July 13.

Folkmann, S., \& Lazarus, R. S. (1988). Coping as a mediator of emotion. Journal of Personality and Social Psychology, 54(3), 466-475. doi: 10.1037/ 0022-3514.54.3.466

Ghazali, D. A., Darmian-Rafei, I., Ragot, S., \& Oriot, D. (2018). Performance under stress conditions during multidisciplinary team immersive pediatric simulations. Pediatric Critical Care Medicine, 19(6), 1-9. doi: 10.1097/PCC.0000000000001473

Gross, J. J. (1998). The emerging field of emotion regulation: An integrative review. Review of General Psychology, 2, 271-299. doi: 10.1037/10892680.2.3.271

Gross, J. J. (2015). Emotion regulation: Current status and future prospects. Psychological Inquiry, 26(1), 1-26. doi: 10.1080/1047840X.2014.940781

Guest, G., MacQueen, K. M., \& Namey, E. E. (2011). Applied thematic analysis. Los Angeles: SAGE. doi: $10.4135 / 9781483384436$

Hagemann, T., Levenson, R. W., \& Gross, J. J. (2006). Expressive suppression during an acoustic startle. Psychophysiology, 43(1), 104-112. doi: 10.1111/ j.1469-8986.2006.00382.x

Harvey, A., Bandiera, G., Nathens, A. B., \& LeBlanc, V. R. (2012). The impact of stress on resident performance in simulated trauma scenarios. The Journal of Trauma and Acute Care Surgery, 72(2), 497-503. doi: 10.1097/TA.0b013e31821f84be

Klein, G. (1997). The effect of acute stressors on decision making. In J. E. Driskell \& E. Salas (Eds.), Stress and Human Performance (pp. 49-83). Hove: Psychology Press.

Klein, G. (2008). Naturalistic decision making. Human Factors, 50(3), 456-460. doi: 10.1518/ $001872008 \times 288385$

Kodate, N., Ross, A. J., Anderson, J. E., \& Flin, R. (2012). Non-Technical Skills (NTS) for enhancing patient safety: Achievements and future directions. Japanese Journal of Quality and Safety in Healthcare, 7(4), 360-370. 
Kohn, L. T., Corrigan, J. M., \& Donaldson, M. S. (2000) To err is human: Building a safe health system. Washington DC: National Academies Press.

Koole, S. L. (2009). The psychology of emotion regulation: An integrative review. Cognition \& Emotion, 23(1), 4-41. doi: 10.1080/ 02699930802619031

Koole, S. L., \& Rothermund, K. (2011). "I feel better but I don't know why": The psychology of implicit emotion regulation. Cognition and Emotion, 25(3), 389-399. doi: 10.1080/02699931.2010. 550505

Koole, S. L., \& Veenstra, L. (2015). Does emotion regulation occur only inside people's heads? Toward a situated cognition analysis of emotion-regulatory dynamics. Psychological Inquiry, 26, 6168. doi: 10.1080/1047840X.2015.964657

Krage, R., Zwaan, L., Len, L. T. S., Kolenbrander, M. W., Van Groeningen, D., Loer, S. A., ... \& Schober, P. (2017). Relationship between non-technical skills and technical performance during cardiopulmonary resuscitation: Does stress have an influence?. Emergency Medicine Journal, 34(11), 728733. doi: 10.1136/emermed-2016-205754

Kross, E., Gard, D., Deldin, P., Clifton, J., \& Ayduk, O. (2012). „Asking why" from a distance: Its cognitive and emotional consequences for people with major depressive disorder. Journal of Abnorma Psychology, 121(3), 559-569. doi: 10.1037/ a0028808

Kuhl, J., Kazén, M., \& Koole, S. (2007). Putting selfregulation theory into practice: A user's manual. Applied Psychology: An International Review, 55(3), 408-418. doi: 10.1111/j.1464-0597.2006. 00260.x

Lazarus, R. S., \& Folkmann, S. (1984). Stress, appraisal, and coping. New York: Springer. doi 10.1007/978-1-4419-1005-9 215

Manera, V., Samson, A. C., Pehrrs, C., Lee, I. A., \& Gross, J. J. (2014, July 21). The eyes have it: The role of attention in cognitive reappraisal of social stimuli. Emotion. Advance online publication. doi: 10.1037/a0037350

Maule, J. A. (1997). Strategies for adapting to time pressure. In R. Flin, E. Salas, M. Strub, \& L. Martin (Eds.), Decision making under stress: The emerging themes and applications (pp. 271-279). Farnham: Ashgate.

Miller, J., \& Schwarz, W. (2014). Brain signals do not demonstrate unconscious decision making: An integration based on graded conscious awareness Consciousness and Cognition, 24, 12-21. doi: 10.1016/j.concog.2013.12.004

Mosier, K. L., \& Fischer, U. (2010). The role of affect in naturalistic decision making. Journal of Cogni- tive Engineering and Decision Making, 4, 240255. doi: $10.1518 / 155534310 \times 12844000801122$

Nisbett, R. E., \& Wilson, T. D. (1977). Telling more than we can know: Verbal reports on mental processes. Psychological Review, 84(3), 231-259. doi: 10.1037/0033-295X.84.3.231

Ochsner, K., \& Gross, J. J. (2008). Cognitive emotion regulation: Insights from social cognitive and affective neuroscience. Current Dicretions in Psychological Science, 17(2), 153-158. doi: 10.1111/ j.1467-8721.2008.00566.x

Orasanu, J. (1997). Stress and naturalistic decision making: Strengthening the weak links. In R. Flin, E. Salas, M. Strub, \& L. Martin, L. (Eds.), Decision making under stress: The emerging themes and applications (pp. 43-66). Farnham: Ashgate.

Pavlidis, I., Tsiamyrtzis, P., Shastri, D., Wesley, A., Zhou, Y., Lindner, P., ... \& Bass, B. (2012). Fast by nature-how stress patterns define human experience and performance in dexterous tasks. Scientific Reports, 2, 305. doi: 10.1038/srep00305

Peňa-Sarrionandia, A., Mikolajczak, M., \& Gross, J. J. (2015). Integrating emotion regulation and emotional intelligence tradition: A meta-analysis. Frontiers in Psychology, 6, 1-27. doi: 10.3389/ fpsyg.2015.00160

Pilárik, L., \& Sarmany-Schuller, I. (2011). Personality predictors of decision-making of medical rescuers. Studia Psychologica, 53(2), 175-184.

Rice, T. R., \& Hoffman, L. (2014). Defense mechanisms and implicit emotion regulation: A comparison of a psychodynamic construct with one from contemporary neuroscience. Journal of the American Psychoanalytic Association, 62(4), 693-708. doi: $10.1177 / 0003065114546746$

Richards, J. M., \& Gross, J. J. (2000). Emotion regulation and memory: The cognitive costs of keeping one's cool. Journal of personality and social psychology, 79(3), 410-424. doi: 10.1037//00223514.79.3.410

Sexton, J. B. (2000). Error, stress, and teamwork in medicine and aviation: Cross sectional surveys. BMJ 2000; 320:745. doi: 10.1136/bmj.320. 7237.745

Sheppes, G., Catran, E., \& Meiran, N. (2009). Reappraisal (but not distraction) is going to make you sweat: Physiological evidence for self-control effort. International Journal of Psychophysiology, 71(2), 91-96. doi: 10.1016/j.ijpsycho.2008.06.006

Shields, A., \& Flin, R. (2012). Paramedics' non-technical skills: A literature review. Emergency Medicine Journal, 30, 350-354. doi: 10.1136/emermed2012-201422

Tamir, M. (2016). Why do people regulate their emotions? A taxonomy of motives in emotion regula- 
tion. Personality and Social Psychology Review, 20(3), 199-222. doi: 10.1177/1088868315586325 Taylor, G. J., Bagby, R. M., \& Parker, J. D. A. (1999). Disorders of affect regulation: Alexithymia in medical and psychiatric illness. Cambridge: Cambridge University Press. doi: 10.1017/ CBO9780511526831

Uramatsu, M., Fujisawa, Y., Mizuno, S., Souma, T., Komatsubara, A., \& Miki, T. (2017). Do failures in non-technical skills contribute to fatal medical accidents in Japan? A review of the 2010-2013 national accident reports. BMJ Open, 7, e013678. doi: 10.1136/bmjopen-2016-013678

van Dillen, L. F., \& Koole, S. L. (2007). Clearing the mind: A working memory model of distraction from negative emotion. Emotion, 7(4), 715-723. doi: 10.1037/1528-3542.7.4.715

Wallbott, H. G. (1998). Bodily expression of emotion. European Journal of Social Psychology, 28, 879896. doi: 10.1002/(SICI)1099-0992(1998110)28: 6\%3C879::AID-EJSP901\%3E3.0.CO;2-W
Webb, T. L., Miles, E., \& Sheeran, P. (2012). Dealing with feeling: A meta-analysis of the effectiveness of strategies derived from the process model of emotion regulation. Psychological Bulletin, 138(4), 775-808. doi: 10.1037/a0027600

Weinberger, D. A. (1990). The construct validity of repressive coping style. In J. L. Singer (Ed.), Repression and dissociation: Implications for personality theory, psychopathology, and health (pp. 337-386). Chicago: The University of Chicago Press. doi: 10.1176/ajp.150.1.159

Wiegmann, D., Faaborg, T., Boquet, A., Detwiler, C., Holcomb, C., \& Shappel, S. (2005). Human error and general aviation accidents: $A$ comprehensive, fine-grained analysis using HFACS. Washington DC: Federal Aviation Administration.

Yiend, J. (2010). The effects of emotion on attention: A review of attentional processing of emotional information. Cognition and Emotion, 24(1), 3-47. doi: 10.1080/02699930903205698

\section{Appendix}

Appendix 1 Brief codebook for emotional behaviour on video records

\begin{tabular}{|c|c|c|}
\hline \multirow{2}{*}{$\begin{array}{l}\text { No emotional } \\
\text { reaction }\end{array}$} & Definition & No visible change in person's behavior. \\
\hline & Signs & No visible change compared to neutral valence and arousal. \\
\hline \multirow[b]{2}{*}{ Attunement } & Definition & $\begin{array}{l}\text { Attempt to understand patient's distress through perception } \\
\text { and mirroring of his emotional state. }\end{array}$ \\
\hline & Signs & $\begin{array}{l}\text { Visually scanning patient's face, adjustment of facial } \\
\text { expression and body posture to patient, attunement of speech } \\
\text { pace to patient's mood. }\end{array}$ \\
\hline \multirow{2}{*}{$\begin{array}{l}\text { Conversational } \\
\text { smile }\end{array}$} & Definition & $\begin{array}{l}\text { Social smile invoked from a communication between } \\
\text { protagonists. }\end{array}$ \\
\hline & Signs & $\begin{array}{l}\text { Raised angle labials, some sign of a genuine smile is missing } \\
\text { (most typically raising cheeks). }\end{array}$ \\
\hline \multirow{2}{*}{ Smile } & Definition & Spontaneous positive reaction to a humorous situation. \\
\hline & Signs & Raised angle labials, raised cheeks. \\
\hline \multirow[b]{2}{*}{ Alertness } & Definition & Increased sensitivity to environmental stimuli. \\
\hline & Signs & $\begin{array}{l}\text { Quick reaction to environmental stimulus, visual scanning of } \\
\text { surroundings. }\end{array}$ \\
\hline \multirow[b]{2}{*}{ Emergency } & Definition & Quick and decisive action with a clear purpose. \\
\hline & Signs & $\begin{array}{l}\text { Quick reaction to an emerged situation, movement towards a } \\
\text { goal or patient, decisive and brisk commanding of colleagues, } \\
\text { fluid execution of procedures. }\end{array}$ \\
\hline
\end{tabular}


Appendix 1 continued

\begin{tabular}{|c|c|c|}
\hline \multirow{2}{*}{ Fright } & Definition & Quick scared reaction to a possibly dangerous situation. \\
\hline & Signs & Dodge backwards, possible vocal reaction. \\
\hline \multirow[b]{2}{*}{ Freeze reaction } & Definition & Absolute cessation of a current action. \\
\hline & Signs & $\begin{array}{l}\text { Being stuck in a certain body posture, remaining in a position } \\
\text { of observer. }\end{array}$ \\
\hline \multirow[b]{2}{*}{ Fear / Worry } & Definition & Caution in a contact with potentially endangering stimulus. \\
\hline & Signs & $\begin{array}{l}\text { Keeping distance from potential danger, being cautious but } \\
\text { not stuck, possibly a scared facial expression (eyes: AU } 5 \text { - } \\
\text { upper lids raiser, AU } 7 \text { - lids tight; mouth: AU } 20 \text { lip stretcher, } \\
\text { or } 25 \text { - lips part). }\end{array}$ \\
\hline \multirow[b]{2}{*}{ Nervousness } & Definition & $\begin{array}{l}\text { Agitation and a tendency to act even if a situation is currently } \\
\text { calm. }\end{array}$ \\
\hline & Signs & $\begin{array}{l}\text { Body movements (jiggling, goalless arm movements), } \\
\text { touching one's own body, clumsy and inarticulate speech, } \\
\text { avoiding eye contact. }\end{array}$ \\
\hline \multirow[b]{2}{*}{ Confusion } & Definition & A tendency to do multiple tasks at once. \\
\hline & Signs & $\begin{array}{l}\text { Sudden change of goal or direction, indecisiveness between } \\
\text { two options, shuffling one's feet, gazing in multiple directions } \\
\text { in a short time period. }\end{array}$ \\
\hline \multirow[b]{2}{*}{ Doubt } & Definition & Being unsure about the chosen course of action. \\
\hline & Signs & $\begin{array}{l}\text { Heading towards a specific goal, but hesitating, asking } \\
\text { questions, making sure of the legitimacy of chosen procedure. }\end{array}$ \\
\hline \multirow{2}{*}{ Doubtful smile } & Definition & $\begin{array}{l}\text { Slight smile expressing insecurity about the present social } \\
\text { situation. }\end{array}$ \\
\hline & Signs & $\begin{array}{l}\text { Slightly raised angle labials, downcast eyes or avoiding eye } \\
\text { contact, short duration. }\end{array}$ \\
\hline \multirow[b]{2}{*}{ Relieving smile } & Definition & Smile with a function of easing stress and pressure. \\
\hline & Signs & $\begin{array}{l}\text { Raised angle labials, following after visible tension, possibly } \\
\text { accompanied by a sigh, possible absence of raised cheeks } \\
\text { (AU 6). }\end{array}$ \\
\hline \multirow{2}{*}{ Ironic smile } & Definition & $\begin{array}{l}\text { Smile communicating devaluation of the person who is being } \\
\text { addressed. }\end{array}$ \\
\hline & Signs & $\begin{array}{l}\text { Pulling angle labials inside (AU } 14 \text { dimpler), possibly just on } \\
\text { one side, possibly accompanied by raised eyebrows. }\end{array}$ \\
\hline \multirow[t]{2}{*}{ Sarcasm } & Definition & $\begin{array}{l}\text { Verbal communication of one's authority and position above } \\
\text { the other. }\end{array}$ \\
\hline & Signs & Joking on someone else's account. \\
\hline \multirow{2}{*}{ Joking } & Definition & Humorous relief of situation's tension. \\
\hline & Signs & Verbally communicating humorous remarks and allusions. \\
\hline \multirow{2}{*}{ Frustration } & Definition & $\begin{array}{l}\text { Slightly angered emotional reaction to an aversive condition in } \\
\text { the situation. }\end{array}$ \\
\hline & Signs & $\begin{array}{l}\text { Headshaking, cessation of current action, sigh, raised voice, } \\
\text { defense against the trigger. }\end{array}$ \\
\hline
\end{tabular}


Appendix 1 continued

\begin{tabular}{|l|l|l|}
\hline \multirow{3}{*}{ Helplessness } & Definition & Inability to execute the desirable action. \\
\cline { 2 - 3 } & Signs & $\begin{array}{l}\text { Loss of initiative, withdrawal, choosing different } \\
\text { procedure/subtask. }\end{array}$ \\
\hline \multirow{2}{*}{ Attenuation } & Definition & Realization of the weight of overcome task/subtask. \\
\cline { 2 - 3 } Relief & Signs & Complete lack of action or slowed down movement. \\
\hline \multirow{4}{*}{ Shamelessness } & Definition & Dissolution of tension. \\
\cline { 2 - 3 } & Signs & Sigh, relaxation of arms and shoulders. \\
\cline { 2 - 3 } & Definition & Not reacting to a relevant stimulus. \\
\hline \multirow{3}{*}{ Disappointment } & $\begin{array}{l}\text { Ignoring or underestimating a critical situation, attentional } \\
\text { deployment, attending another aspect of the situation. }\end{array}$ \\
\cline { 2 - 3 } & Signs & Appraising one's previous behavior as socially unacceptable. \\
\cline { 2 - 3 } & Signs & $\begin{array}{l}\text { Redness in face, descent of body posture, downcast eyes or } \\
\text { avoiding eye contact, behavioral tendency to not be in the } \\
\text { center of attention. }\end{array}$ \\
\cline { 2 - 3 } Surprise & Signs & $\begin{array}{l}\text { Slouching body posture (head and shoulders), inhibition of all } \\
\text { activity, possibly sad/relaxed facial expression. }\end{array}$ \\
\hline & Definition & Reaction to an unexpected event. \\
\cline { 2 - 3 } & Signs & $\begin{array}{l}\text { Acquisition of new information (listening or gazing), open } \\
\text { mouth and wide-open eyes, movement towards the source of } \\
\text { surprise. }\end{array}$ \\
\hline
\end{tabular}


Appendix 2 Illustration of a time unit on timeline of paramedic crew leader's task experience

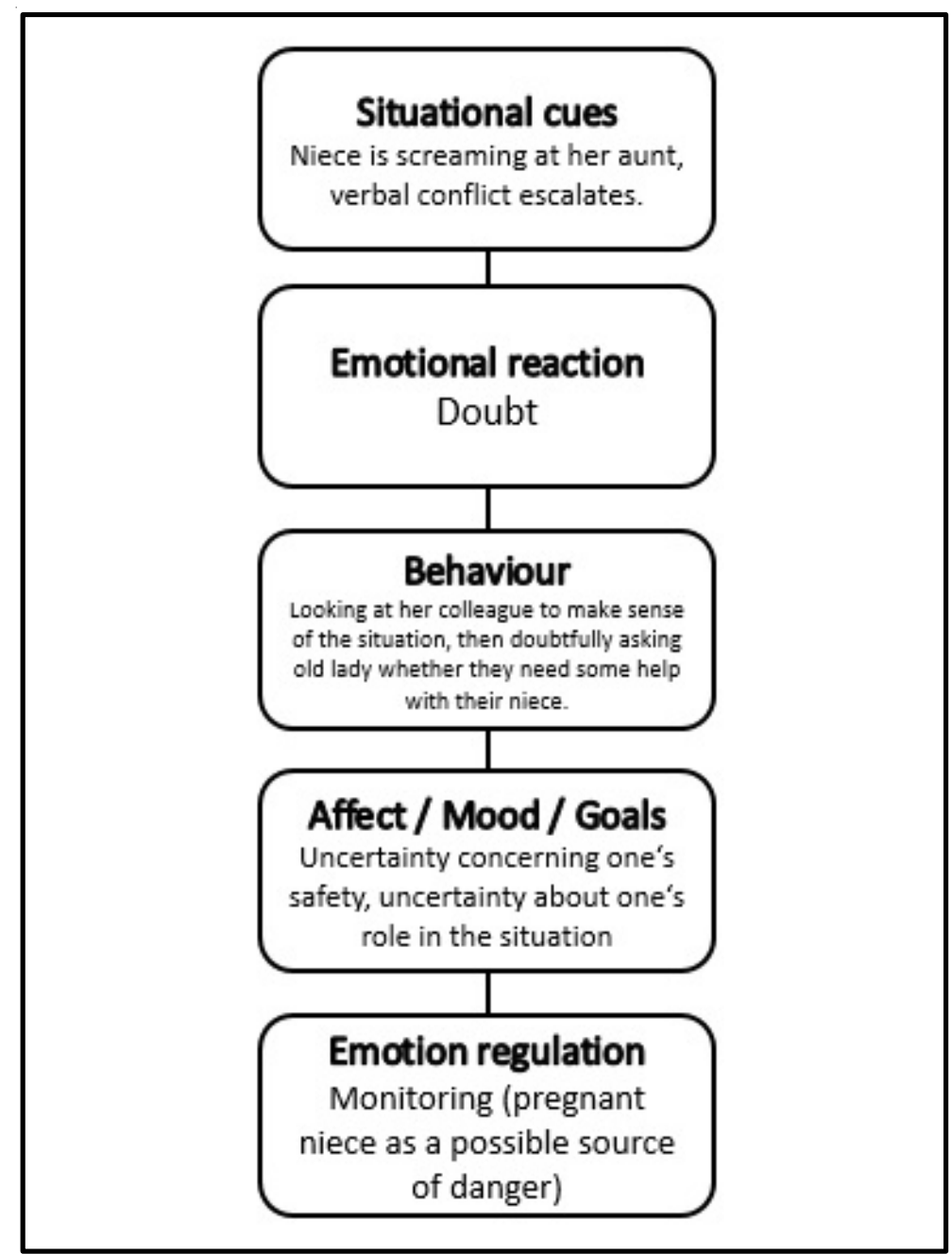

